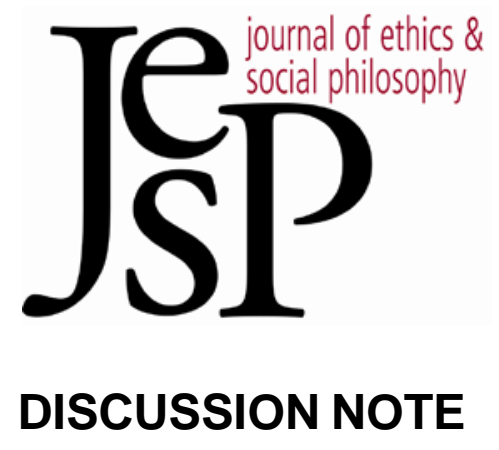

\title{
Reasons-Responsiveness and Time Travel
}

\author{
BY YISHAI COHEN
}

JOURNAL OF ETHICS \&SOCIAL PHILOSOPHY

DISCUSSION NOTE | JANUARY 2015

URL: WWW.JESP.ORG 


\section{Reasons-Responsiveness and Time Travel}

Yishai Cohen

$\mathrm{J}$

OHN MARTIN FISCHER AND MARK RAVIZZA offer a theory of moral responsibility in their seminal (1998) work that continues to be a promising route to the compatibility of determinism and responsibility. Fischer and Ravizza (henceforth F\&R) motivate their theory partly on the basis of Frankfurt-style cases (FSCs), which are putative counterexamples to the principle of alternative possibilities (PAP). ${ }^{1}$ More specifically, they take FSCs to show that regulative control - a dual power to either do something or refrain from doing it - is not necessary for responsibility. So PAP is false. Instead, only guidance control - a "one-way" power - is necessary for responsibility. However, alternative possibilities are relevant to assessing whether one possesses guidance control. I argue that F\&R's theory (henceforth Reasons-Responsiveness) is incompatible with the metaphysical possibility of time travel. Before turning to my argument, I will first lay out the basics behind Reasons-Responsiveness.

\section{Reasons-Responsiveness}

F\&R understand guidance control to involve two components: the mechanism $M$ that issues in an agent $S$ 's $\varphi$-ing must be $S$ 's own, and $M$ must be (at least) moderately reasons-responsive. A mechanism $M$ is moderately reasonsresponsive iff $M$ is regularly reasons-receptive and weakly reasons-reactive. A mechanism $M$ that issues in $S$ 's $\varphi$-ing is (at least) regularly reasons-receptive iff there is some set $x$ of nomologically identical worlds ${ }^{2}$ (i.e., worlds with the same laws of nature as the world in which $M$ issues in $S$ 's $\varphi$-ing) in which there is sufficient reason ${ }^{3}$ for $S$ to refrain from $\varphi$-ing, and $S$ recognizes (through $M$ ) that there is sufficient reason to refrain from $\varphi$-ing. ${ }^{4}$ Lastly, a mechanism $M$ that issues in $S$ 's $\varphi$-ing is (at least) weakly reasons-reactive iff there are some worlds that are members of $x$ in which $S$ refrains from $\varphi$-ing (through $M$ ). ${ }^{5}$

So, although an agent $S$ who $\varphi$ s in an FSC cannot refrain from $\varphi$-ing, so long as the mechanism $M$ that issues in $S$ 's $\varphi$-ing is $S$ 's own and $M$ is moderately reasons-responsive, then $S$ is morally responsible for $\varphi$-ing. ${ }^{6}$ With this

${ }^{1}$ Frankfurt (1969).

2 Fischer and Ravizza (1998: 44).

3 At least some of the reasons must be moral reasons (ibid.: 76-81).

${ }^{4} \mathrm{~A}$ further feature of regular reasons-receptivity is that it involves an understandable pattern of receptivity to actual and hypothetical reasons (ibid.: 69-73). For brevity's sake I will not mention this feature of regular reasons-receptivity until section 4.

${ }^{5}$ For a complete overview of moderate reasons-responsiveness, see ibid., ch. 3.

${ }^{6} \mathrm{I}$ ignore the epistemic condition on responsibility given its irrelevance to the discussion at hand. 
basic understanding of Reasons-Responsiveness in place, I now turn to an issue that bears directly upon my argument, viz., the issue of mechanism individuation.

\section{Mechanism Individuation and Intrinsicness}

In order to determine whether a mechanism that issues in an agent's action is moderately reasons-responsive, we need to hold fixed this mechanism when evaluating what occurs in nomologically identical worlds. But how are mechanisms to be individuated? What exactly $d o$ we hold fixed? F\&R explicitly say that the mechanism relevant to assessing an agent's responsibility must be temporally intrinsic or nonrelational, which is to be understood as follows: "if a mechanism $M$ issues in act $A$, then $M$ is relevant to the agent's guidance control of $A$ only if $M$ 's operating does not entail that $A$ occurs." $7 \mathrm{~F} \& \mathrm{R}$ take this necessary condition for a mechanism being relevant to the agent's guidance control to rule out the possibility of the preemptive intervener of an FSC even partly constituting $S$ 's moderately reasons-responsive mechanism. For the presence of the preemptive intervener is supposed to entail that $S \varphi$ s. So what are the necessary and sufficient conditions for determining whether a mechanism is relevant to the agent's guidance control? F\&R do not say, though they presuppose that there is some natural way to individuate between mechanisms that are and are not relevant to an agent's guidance control. Might the above necessary condition for a mechanism being relevant to an agent's guidance control be sufficient? No. The fact that $S$ is one mile away from, say, the post office, is surely irrelevant to whether a moderately reasons-responsive mechanism issues in $S$ 's $\varphi$-ing. In other words, $S$ 's extrinsic property of being one mile away from the post office does not even partly constitute a moderately reasons-responsive mechanism $M$ that issues in $S$ 's $\varphi$ ing. This suggests that, according to Reasons-Responsiveness, a moderately reasons-responsive mechanism $M$ that issues in $S$ 's $\varphi$-ing is wholly constituted by $S$ 's intrinsic properties (either all of $S$ 's intrinsic properties or, more likely, some subset thereof). ${ }^{8}$ I will henceforth refer to this position as IntrinsicMechanism. Note that Intrinsic-Mechanism has the following implication: If two agents, $S$ and $S^{*}$, are intrinsic duplicates of one another, and $S$ has a moderately reasons-responsive mechanism, then $S^{*}$ likewise has a moderately reasons-responsive mechanism. ${ }^{9}$

F\&R do not explicitly endorse or reject Intrinsic-Mechanism. However, if they were to reject Intrinsic-Mechanism, the burden would be on them to specify some non-ad hoc criterion for distinguishing between mechanisms that are

7 Ibid.: 47.

${ }^{8}$ Note that nothing I say here hinges upon whether we reify mechanisms.

9 This implication of Intrinsic-Mechanism is consistent with the claim that $S$ and $S^{*}$ may have different histories, such that $S^{\prime}$ 's moderately reasons-responsive mechanism is $S$ 's own, but $S^{*}$ 's moderately reasons-responsive mechanism is not $S^{*}$ 's own. 
and are not moderately reasons-responsive, whereby a moderately reasonsresponsive mechanism can be partly constituted by some of $S$ 's extrinsic properties. Attempting to offer such a criterion would arguably be quite challenging. So, it would be better ceteris paribus for F\&R if they endorsed IntrinsicMechanism. However, as I will argue below, if F\&R accept Intrinsic-Mechanism, they must reject the metaphysical possibility of time travel.

\section{A Time Travel Case}

\section{Consider the following Case 1:10}

Amy lives in a peculiar world for two reasons. First, time travel is nomologically possible (and thus metaphysically possible). Second, individuals in this world have terrifying powers. More specifically, the laws of nature entail that an individual $\mathrm{x}$ can kill another individual $\mathrm{y}$ through a basic mental action, viz., by willing that y dies. However, y can continue to live by performing the basic mental act of willing to nullify x's act. Now, through the use of a time machine, Amy travels 20 years back in time. Amy exits the time machine, and confronts Young Zoe. Amy wills that Young Zoe die. However, Young Zoe wills to nullify Amy's act. So Amy does not succeed in killing Young Zoe. Young Zoe's mental act of willing to nullify Amy's act issues from mechanism $M$, which is moderately reasons-responsive.

If $M$ is moderately reasons-responsive, then there is some set of nomologically identical worlds in which Young Zoe recognizes (through $M$ ) that there is sufficient reason to refrain from nullifying Amy's act. And in some of those worlds, Young Zoe refrains (through $M$ ) from nullifying Amy's act, and thus dies. Now, consider a case like Case 1, except that Amy is replaced with Young Zoe's older self, Old Zoe. Call this Case 2:

Old Zoe lives in a world that is nomologically identical to the world mentioned in Case 1. Now, through the use of a time machine, Old Zoe travels 20 years back in time. Old Zoe exits the time machine and confronts Young Zoe. Old Zoe wills that Young Zoe die. However, Young Zoe wills to nullify Old Zoe's act. So Old Zoe does not succeed in killing Young Zoe. Young Zoe's mental act of nullifying Old Zoe's act issues from mechanism $M^{*}$.

Let us consider the implications of Cases 1 and 2. As a matter of stipulation, Young Zoe has the exact same set of intrinsic properties in Cases 1 and 2.11

10 I owe the inspiration for this case to Joshua Spencer's (2013) ingenious time travel FSC against PAP. While F\&R reject PAP, they nevertheless maintain that alternative possibilities are relevant to assessing an agent's responsibility. For this reason, my argument rests on a case that shares certain structural similarities to Spencer's putative counterexample to PAP. However, despite the fact that Spencer and I employ similar cases against different positions, there is no good reason to think that my argument and Spencer's argument stand or fall together. 
So, given that $M$ is moderately reasons-responsive, it follows from IntrinsicMechanism that $M^{*}$ is likewise moderately reasons-responsive. However, as I will now explain, it cannot be the case that $M^{*}$ is moderately reasonsresponsive.

If $M^{*}$ is moderately reasons-responsive, then there is some set of nomologically identical worlds in which Young Zoe recognizes (through $M^{*}$ ) that there is sufficient reason to refrain from nullifying Old Zoe's act, and in at least some of those worlds Young Zoe refrains from nullifying Old Zoe's act (through $\left.M^{*}\right)$. In that case, for any such world $w$ in which Young Zoe refrains from nullifying Old Zoe's act (through $M^{*}$ ), Young Zoe dies in $w$. However, Young Zoe's dying is incompatible with Old Zoe's existing. More generally, Zoe's existing later than Zoe's death relative to Zoe's personal time is metaphysically impossible. ${ }^{12}$ So there is no nomologically identical world in which Young Zoe refrains from nullifying Old Zoe's act (through $M^{*}$ ). For this reason, it cannot be the case that $M^{*}$ is moderately reasons-responsive. So, if Intrinsic-Mechanism is true, F\&R must reject the metaphysical possibility of time travel.

\section{An Objection}

Consider the following objection: In regard to assessing whether $M^{*}$ is moderately reasons-responsive, we just need to hold fixed the fact that it is someone qualitatively similar to Old Zoe (rather than Old Zoe herself) who wills that Young Zoe die. Consequently, we can maintain that there is a nomologically identical world in which the following is true: (a) someone qualitatively similar to Old Zoe wills that Young Zoe die, (b) Young Zoe refrains (through $M^{*}$ ) from nullifying this person's act, and (c) Young Zoe dies. So we can maintain that $M^{*}$ is moderately reasons-responsive. Thus, F\&R can accept both Intrinsic-Mechanism and the metaphysical possibility of time travel. ${ }^{13}$

My reply is as follows: While we must hold fixed the mechanism that issues in an agent's action when evaluating nomologically identical worlds, this cannot be all that is held fixed. To illustrate, consider what F\&R say about the saber killer case, a case in which a person boarded a ferry and proceeded to kill fellow passengers with a saber. Suppose that the mechanism $\mathrm{X}$ that issued in the saber killer's decision to kill the fellow passengers is such that there is only one possible scenario in which the saber killer recognizes (through $\mathrm{X}$ ) that he thereby has more reason not to kill the fellow passen-

\footnotetext{
11 If for some reason this stipulation turns out to be problematic, it is surely unproblematic to stipulate that in Cases 1 and 2 Young Zoe has the exact same set of intrinsic properties that are even remotely viable candidates for constituting a moderately reasons-responsive mechanism. Moreover, this latter stipulation suffices for my argument to go through.

12 See Lewis (1976: 145-46) on the distinction between external time and personal time.

13 Thanks to an anonymous referee for bringing this consideration to my attention.
} 
gers, and refrains (through X) from killing the fellow passengers. ${ }^{14}$ Suppose, moreover, that the reason in question is that some passenger is smoking a Gambier pipe in the lower cabin, and that this reason is not understandable from a third party's perspective..$^{15}$ In other words, suppose this pattern of reasons-recognition is not even minimally grounded in reality. ${ }^{16}$ In that case, $\mathrm{F} \& \mathrm{R}$ would say that $\mathrm{X}$ - which issued in a decision to kill the fellow passengers - is not moderately reasons-responsive.

The above summary of F\&R's position is consistent with the claim that there is a nomologically identical world in which the saber killer recognizes (through $\mathrm{X}$ ) that he has more reason not to kill different but qualitatively similar passengers (whereby this reason is minimally grounded in reality), and refrains (through $\mathrm{X}$ ) from killing different but qualitatively similar passengers. ${ }^{17}$ So, at least sometimes, the question of how a mechanism might issue in an intentional action that concerns in some manner qualitatively similar yet numerically distinct individuals is irrelevant. Similarly, in regard to Case 2, even if there is a nomologically identical world in which Young Zoe refrains (through $M^{*}$ ) from nullifying the act of someone who is qualitatively similar to Old Zoe, this has no bearing upon whether $M^{*}$ is moderately reasonsresponsive. The more general point is that some things other than the agent's mechanism must be held fixed in order to determine whether in nomologically identical worlds the agent performs or refrains from performing the same intentional action.

\section{Conclusion}

We have seen that the following is an inconsistent triad:

i. A mechanism $M$ is moderately reasons-responsive iff $M$ is regularly reasonsreceptive and weakly reasons-reactive.

ii. Intrinsic-Mechanism: a moderately reasons-responsive mechanism $M$ that issues in $S$ 's $\varphi$-ing is wholly constituted by $S$ 's intrinsic properties.

iii. Time travel is metaphysically possible.

F\&R are explicitly committed to (i). Moreover, a natural interpretation of Reasons-Responsiveness suggests that Intrinsic-Mechanism is true. At any rate, I have suggested that if F\&R were to reject Intrinsic-Mechanism, the burden would be on them to specify some non-ad hoc criterion for distinguishing be-

${ }^{14}$ Fischer and Ravizza (1998: 65).

15 Ibid.: 72.

16 Ibid.: 73 .

17 I am presupposing that a de re reading of "the fellow passengers" determines the individuals being referred to in the saber killer case. If, however, F\&R have a principled reason to adopt a de dicto reading of "the fellow passengers," this is not detrimental for what I wish to argue for here. For even if we adopt a de dicto reading of such phrases, my point still holds for a saber-killer case in which the phrase "the fellow passengers" is replaced with, e.g., "the saber killer's family." 
tween mechanisms that are and are not moderately reasons-responsive, whereby a moderately reasons-responsive mechanism can be partly constituted by some of S's extrinsic properties. Such a criterion, I think, will not come easy. So it appears that Reasons-Responsiveness is in fact incompatible with the metaphysical possibility of time travel. This comes at a cost to the theory. For one of the motivations for Reasons-Responsiveness is that, unlike libertarianism, Reasons-Responsiveness is not threatened by certain propositions that for all we know are true, such as that our world is deterministic. ${ }^{18}$ This motivation becomes somewhat deflated given that Reasons-Responsiveness is likewise threatened by a proposition that for all we know is true, viz., that time travel is metaphysically possible. Moreover, those who are attracted to the metaphysical possibility of time travel thereby have good reason to reject ReasonsResponsiveness in its current form. ${ }^{19,20}$

Yishai Cohen

Syracuse University

Department of Philosophy

yacohen@syr.edu

18 Ibid.: 14-16.

${ }^{19}$ For a defense of the metaphysical possibility of time travel, see, e.g., Dowe (2000). See Artzenius and Maudlin (2002) on the nomological possibility of time travel. Note that if F\&R were to reject the metaphysical possibility of time travel, they also cannot employ Spencer's (2013) time travel FSC against PAP.

${ }^{20}$ For helpful discussion and comments on a previous draft of this paper, I am grateful to John Fischer, Mark Heller and an anonymous referee. 


\section{References}

Arntzenius, F. and Maudlin, T. (2002) "Time Travel and Modern Physics," in C. Callender, ed., Time, Reality and Experience, Cambridge: Cambridge University Press, pp. 169-200.

Dowe, P. (2000) "The Case for Time Travel," Philosopby 3: 441-51.

Fischer, J. M. and Ravizza, M. (1998) Responsibility and Control: A Theory of Moral Responsibility, Cambridge: Cambridge University Press.

Frankfurt, H. (1969) "Alternate Possibilities and Moral Responsibility," The Journal of Philosophy 66: 829-39.

Lewis, D. K. (1976) “The Paradoxes of Time Travel," American Philosophical Quarterly 13: 145 52.

Spencer, J. (2013) "What Time Travelers Cannot Not Do (but Are Responsible for Anyway)," Philosophical Studies 166: 149-62. 